\title{
Políticas Públicas e a democratização do acesso e permanência de alunos/as LGBTTIQ+
}

\author{
Políticas Públicas y la democratización del acceso y la estancia del estudiante \\ $L G B T T I Q+$
}

Public Policies and the democratization of student acess and stay LGBTTIQ+

\author{
Ewerton da Silva Ferreira ${ }^{1}$ \\ Marilice Cortes ${ }^{2}$ \\ Ronaldo Bernardino Colvero ${ }^{3}$ \\ Jaqueline Carvalho Quadrado ${ }^{4}$
}

\section{Resumo}

O presente artigo apresenta as políticas públicas na área da educação com o olhar para a população LGBTTIQ+. O objetivo central é realizar uma retrospectiva a partir das legislações existentes que tratam dos direitos deste grupo, bem como a forma que as políticas públicas se articulam para a garantia destes direitos. Para isso, caminhamos através da interpretação e análise da garantia do direito à educação comtemplada pela Constituição Federal de 1988, e dos documentos que surgiram após esta. Dentre os quais realizaremos uma análise do Programa Brasil sem Homofobia, e seus impactos no pensamento de novas políticas públicas para a população LGBTTIQ+. Também no campo das políticas públicas, será analisado o Plano Nacional de Promoção da Cidadania e Direitos Humanos dos LGBT, e através destes buscamos realizar uma correlação entre a Constituição Federal, e o que dispõem estes documentos ora vigentes, analisando sua eficiência ou ineficiência no âmbito da educação.

Palavras-Chave: Educação; Gênero; Políticas Públicas; Programa Brasil sem Homofobia.

\section{Resumen}

Este artículo apresenta políticas públicas em el área de educación com vistas a la población LGBTTIQ+. El objetivo central es llevar a cabo uns retrospectiva basada em la leyes existentes que abordan los derechos de este grupo, así como la forma em que se articulan las políticas públicas para garantizar estos derechos. Para ello, analizamos la interpretación y el análisis de la garantia del derecho a la educacíon contemplada em la Constitución Federal de 1988, y de los documentos que surgieron después de ella. Entre los cuales realizaremos um análisis del Programa Brasil sin Homofobia y sus impactos em el pensamento de nuevas políticas públicas para la población LGBTTIQ+. Também em el campo de las políticas públicas, se analizará el Plan Naciona para la Promoción de la Ciudadanía LGBT y los Derechos Humanos, y a através de estos buscaremos estabelecer uma correlación entre la Constitución Federal y lo que estos documentos em vigência, analisado su eficiência o ineficiência em el contexto de la educación.

Palabras claves: Educación; Género; Políticas Públicas; Programa Brasil sin Homofobia.

Abstract

\footnotetext{
${ }^{1}$ Mestrando em Políticas Públicas; Universidade Federal do Pampa; São Borja, Rio Grande do Sul, Brasil; Email: ewertonferreira266@gmail.com

${ }^{2}$ Mestra em Políticas Públicas; Universidade Federal do Pampa; São Borja, Rio Grande do Sul, Brasil; E-mail: marilicecortes1@gmail.com

${ }^{3}$ Doutor em História; Universidade Federal do Pampa; São Borja, Rio Grande do Sul, Brasil; E-mail: ronaldocolvero@unipampa.edu.br

${ }^{4}$ Doutora em Sociologia; Universidade Federal do Pampa; São Borja, Rio Grande do Sul, Brasil; E-mail: jaquelinequadrado@unipampa.edu.br
} 
This article presents public polices in the area of education with a view to the LGBTTIQ+ population. The central objective is to carry out a retrospective based on the existing laes that deal with the rights of this group, as well as the way that public policies are articulated to guarantee these rights. For that, we walked through the interpretation and analysis of the guarantee of the right $t$ education contemplated by the Federal Constitution of 1988, and of the documents that emerged after it. Among which we will carry out an analysis of the Brazil without Homophobia Program, and its impacts on the thinking of new public policies of the LGBTTIQ+ population. Also in the field of public policies, the National Plan for the Promotion of LGBT Citizenship and Human Rights will be analyzed, and through these we seek t establish a correlation between the Federal Constitution, and what these documents have in place, analyzing their efficiency or inefficiency in the context of education.

Keywords: Education. Gender; Public Policy; Brazil without Homophobia Program.

\section{Introdução}

A Constituição Federal de 1988, institui o Brasil como um Estado Democrático de Direito e efetivou aos cidadãos diversos direitos, dentre eles: os fundamentais, sociais, políticos. $\mathrm{O}$ artigo $1^{\circ}$ da Constituição garante a cidadania e a dignidade da pessoa humana como fundamento do Estado. Já o artigo $3^{\circ}$, pontua como objetivos fundamentais da República Brasileira a construção de uma sociedade livre, justa, solidária e a promoção do bem de todos, sem preconceitos de origem, raça, sexo, cor, idade ou quaisquer outras formas de discriminação.

A Carta Magna pontua como direitos sociais de todos os brasileiros as garantias que estavam até então estavam fechadas a uma elite, a qualeram detentora do poder econômico ou estavam ligada à igreja.

Art. $6^{\circ}$ São direitos sociais a educação, a saúde, a alimentação, o trabalho, a moradia, o transporte, o lazer, a segurança, a previdência social, a proteção à maternidade e à infância, a assistência aos desamparados, na forma desta Constituição (BRASIL, 1988, s/p).

Diante de todos os direitos que outrora foram negados à população brasileira teremos como foco nesse artigo o direito à educação, sobretudo, com um olhar voltado para as políticas públicas que foram criadas a partir do novo texto constitucional.

Embora as Constituições anteriores pontuassem o direito à educação, não existia uma efetividade da garantia desses direito aos menos favorecidos economicamente, e nem aos que fugissem da norma construída ao longo dos anos através do pensamento cristão. Essa não valorização da diversidade de sujeitos e pensamentos "decorre de um processo histórico que não considerou as diferentes etnias na formação do nosso país, o que contribuiu para segregação e a marginalização das minorias de todos aqueles vistos como diferentes" (SAVELI, 2010, p. 138). 
A garantia do direito à educação ampliou a quantidade de escolas públicas em todo o território nacional. Em vista disso,possibilitou a criação de políticas públicas para efetivação do acesso e da permanência dos sujeitos na escola como preconiza os artigos 205 e 206 da Constituição.

\begin{abstract}
Art. 205 - A educação, direito de todos e dever do Estado e da família, será promovida e incentivada com a colaboração da sociedade, visando ao pleno desenvolvimento da pessoa, seu preparo para o exercício da cidadania e sua qualificação para o trabalho.

Art. 206 - O ensino será ministrado com base nos seguintes princípios:

I - igualdade de condições para o acesso e permanência na escola;

II - liberdade de aprender, ensinar, pesquisar e divulgar o pensamento, a arte e o saber;

III - pluralismo de ideias e de concepções pedagógicas, e coexistências de instituições públicas e privadas de ensino;

IV - gratuidade do ensino público em estabelecimentos oficiais;

V- valorização dos profissionais do ensino, garantido, na forma da lei, plano de carreira para o magistério público, com piso salarial profissional e ingresso exclusivamente por concurso público de provas e títulos, assegurando regime jurídico único para todas as instituições mantidas pela União (BRASIL, 1998, s/p).
\end{abstract}

Com o advento da Constituição esta permitiu que outros documentos e leis fossem elaborados, visando a garantia do texto constitucional. Cabe destacar a Lei $\mathrm{n}^{\circ} 8.069$ de 13 julho de 1990 - o Estatuto da Criança e do Adolescente ${ }^{5}$ - ECA que promulgou diversas garantias e dentre estas, a escolarização de crianças e adolescentes, especialmente, no período considerado regular.

O ECA em seu artigo $4^{\circ}$ dispõe: a) preferência na formulação e na execução das políticas sociais públicas; b) destinação privilegiada de recursos públicos nas áreas relacionadas com a proteção à infância e à juventude. Os apontamentos realizados através do ECA, são fundamentais na formulação de políticas públicas que serão apresentadas posteriormente por diversos setores da sociedade, porém em sua maioria não conseguiram lograr êxito. A lei em vogapontua ainda que:

Art. $5^{\circ}$ Nenhuma criança ou adolescente será objeto de qualquer forma de negligência, discriminação, exploração, violência, crueldade e opressão, punido na forma da lei qualquer atentado, por ação ou omissão, aos seus direitos fundamentais (BRASIL, 1990, s/p).

\footnotetext{
${ }^{5}$ O Estatuto da Criança e do Adolescente foi criado através da Lei no 8.069, de julho de 1990. O documento é um conjunto de leis que garantem os direitos das crianças e dos adolescentes no Brasil, com base nas diretrizes previstas na Constituição Federal de 1988 e nas normativas internacionais propostas pela Organização das Nações Unidas - ONU. O ECA serve como um mecanismo de proteção das crianças (até 12 anos de idade) e adolescentes (entre 12 e 18 anos), delimitando direitos e deveres.
} 
Seguindo a mesma perspectiva da Constituição de 1988 e do Estatuto da Criança e do Adolescente, foi aprovada a Lei $\mathrm{n}^{\circ} 9.394$ de 20 de dezembro de 1996, que estabeleceu as diretrizes e bases para educação nacional. Dentre as orientações apresentadas pela lei estão:

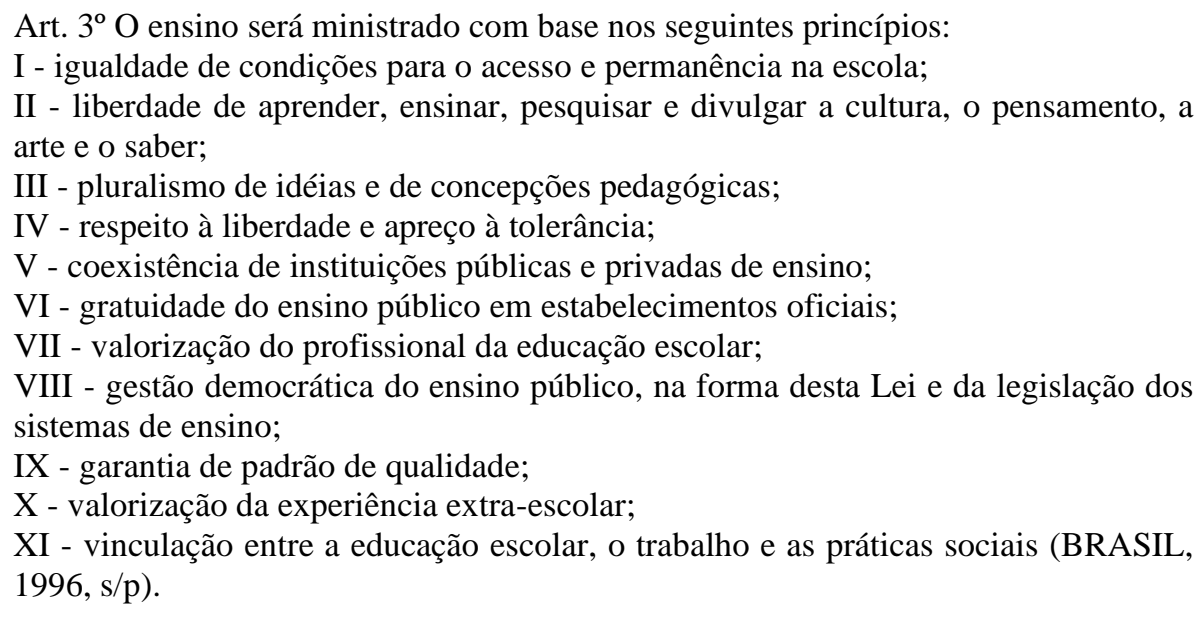

Sob o viés de pensar na garantia do acesso e a permanência das crianças e adolescentes no meio educacional, foram criadas medidas para o cumprimento da Constituição, tais como: merenda escolar, o Plano Nacional do Livro Didático e a inserção temas emergentes e transversais, que chegaram à escola com os novos sujeitos que ocupam os bancos escolares.

Na tentativa da aplicabilidade de novas políticas de inclusão dos grupos sociais que estiveram durante muito tempo fora do ambiente escolar, em 1997 o Ministério da Educação lançou os Parâmetros Curriculares Nacionais - PCN com objetivo de orientar a ação dos professores nas diversas áreas do conhecimento e nos temas transversais. Neste texto analisaremos apenas a parte do documento que tange a Orientação Sexual.

O PCN elucida que devido ao crescimento do movimento feminista e a elevação do número de casos de HIV/AIDS ${ }^{2}$ no Brasil nos 60, e da concepção que a sexualidade aflora em todas as faixas etárias e, portanto, ignorar, ocultar ou reprimir é apenas uma tendência de profissionais e de setores que acreditam que é apenas papel da família realizar a abordagem do tema com os adolescentes. De acordo com o documento:

A Orientação Sexual na escola é um dos fatores que contribui para o conhecimento e valorização dos direitos sexuais e reprodutivos. Estes dizem respeito à possibilidade de que homens e mulheres tomem decisões sobre sua fertilidade, saúde reprodutiva e criação de filhos, tendo acesso às informações e aos recursos necessários para implementar suas decisões. Esse exercício depende da vigência de políticas públicas que atendam a estes direitos. (BRASIL, 1997, p. 293). 
O conhecimento produzido do campo teórico sobre os estudos feministas e das relações de gênero compreendem uma pluralidade em seus conceitos. De acordo, com Louro (2002) utilizaremos a palavra "sexo" para nos referirmos ao sexo biológico, ou seja, macho e fêmea, sendo estas características biológicas do indivíduo. Já a sexualidade é construção social dos indivíduos em manifestarem seus desejos sexuais e afetivos. O gênero é a construção de padrões considerados masculinos e femininos.

A construção da identidade do aluno está baseada na construção da imagem de um adulto referência, como evidencia Seffner (2017) através das práticas e da reprodução de saberes. Nesse sentido, os Parâmetros Curriculares Nacionais destaca sobre a Orientação Sexual que:

\begin{abstract}
Assim como a inteligência, a sexualidade será construída a partir das possibilidades individuais e de sua interação com o meio e a cultura. Os adultos reagem de uma forma ou de outra, aos primeiros movimentos exploratórios que a criança faz na região genital e aos jogos sexuais com outras crianças. As crianças recebem então, desde muito cedo, uma qualificação ou "julgamento" do mundo adulto em que estão imersas, permeado de valores e crenças atribuídos à sua busca de prazer, os quais estarão presentes na sua vida psíquica (BRASIL, 1997, p. 296).
\end{abstract}

A necessidade de abordagem dos temas emergentes no ambiente escolar torna-se evidente, sobretudo, na garantia de cumprir os artigos da Lei de Diretrizes e Bases, que apontam sobre a garantia de acesso e permanência dos estudantes na escola. Nessa perspectiva é fundamental compreender que não apenas a presença dos estudantes em sala de aula e alimentação nas escolas garante a permanência deste no ambiente escolar.

Cabe aqui um destaque que na década 1990, com a mudança do entendimento da Organização Mundial da Saúde- OMS, sobre o entendimento da homossexualidade como uma condição humana e retirando o "homossexualismo" da Classificação Internacional de Doenças - CID, diversos grupos, especialmente, o movimento Lésbico e Gay "saíram do armário" e ampliaram as lutas pelos seus direitos. Com esse novo grupo colocando "a cara no sol $^{7}$, , discussões que outrora eram consideradas tabus chegam a escola e precisam ser abordadas. O PCN - Orientação Sexual destaca que

\footnotetext{
${ }^{6}$ Termo utilizado até 1990 para classificar a homossexualidade. Tal denominação entendia como uma doença e incluía na Classificação Internacional de Doenças.

${ }^{7}$ Gíria utilizada pela comunidade LGBTTIQ+ para mencionar um ato de coragem e de exposição. A utilização desse termo nesse texto é compreendida pelos autores como um ato político.
} 
Com a inclusão da Orientação Sexual nas escolas, a discussão de questões polêmicas e delicadas, como masturbação, iniciação sexual, o "ficar" e o namoro, homossexualidade, aborto, disfunções sexuais, prostituição e pornografia, dentro de uma perspectiva democrática e pluralista, em muito contribui para o bem-estar das crianças, dos adolescentes e dos jovens na vivência de sua sexualidade atual e futura (BRASIL, 1997, p. 293).

Dessa forma, abordagens dos temas que chegam à escola com os novos estudantes e com a nova geração é indispensável para produção de uma escola mais justa, inclusiva e que tenha uma preocupação que vá além da transferência de conhecimento do professor ao aluno, mas que se constitua de um processo de mediação do conhecimento e, acima de tudo, forneça uma educação para o preparo do exercício da cidadania, como preconiza a Lei de Diretrizes e Bases - LDB.

Dentre os temas que chegam à escola, optamos em aprofundar nosso olhar sobre o gênero e sexualidade na escola. Tal escolha baseia-se em uma experiência pessoal por parte de um dos autores que vivenciou um processo de exclusão dentro da escola ao longo de sua trajetória na educação básica e hoje através de uma reflexão não consegui verificar dentro da proposta do currículo escolar ofertado na época, uma abordagem satisfatória da temática. Em segundo plano por compreender a importância das políticas públicas criadas para a promoção dos direitos das pessoas LGBTTIQ+ ${ }^{8}$.

\section{Programa Brasil sem Homofobia}

O Brasil em 2004 criou o Programa Brasil sem Homofobia ${ }^{9}$, com objetivo de articulação da política de promoção dos direitos dos homossexuais. A iniciativa buscava uma congeminação para a elaboração do Plano de Combate à discriminação contra homossexuais, para tanto o plano pontuava diversas ações, a saber:

a) apoio a projetos de fortalecimento de instituições públicas e nãogovernamentais que atuam na promoção da cidadania homossexual e/ou no combate à homofobia;

b) capacitação de profissionais e representantes do movimento homossexual que atuam na defesa de direitos humanos;

c) disseminação de informações sobre direitos, de promoção da auto-estima homossexual; e

\footnotetext{
${ }^{8}$ Lésbicas, Gays, Bissexuais, Travestis, Transexuais, Intersexuais, Intersexuais, Queer e outras identidades e orientações sexuais.

${ }^{9}$ O Programa Brasil Sem Homofobia foi lançado em 2004, a partir de uma série de discussões entre o Governo Federal e a sociedade civil organizada (Organizações Não-Governamentais, entre outras), com o objetivo de promover a cidadania e os direitos humanos de lésbicas, gays, bissexuais, travestis e transexuais (LGBT), a partir da equiparação de direitos e do combate à violência e à discriminação.
} 
d) incentivo à denúncia de violações dos direitos humanos do segmento GLTB (BRASIL, 2004, p. 11).

Além do supracitado, o programa é o primeiro documento no Brasil a pontuar realização de políticas públicas voltadas a população LGBTTIQ que vão além da área da saúde. O documento orientava a inclusão de não discriminação por orientação sexual a serem implementadas (integral ou parcialmente) pelos diferentes Ministérios e Secretarias do Governo Federal. Também deveria haver subsídio para ampliação de elaboração, implementação, avaliação das políticas públicas, sobretudo, na área da educação para a qual está voltado nosso olhar de pesquisa. Nesse sentido, ele é bastante enfático em seus objetivos ao sinalizar

\begin{abstract}
A produção de conhecimento para subsidiar a elaboração, implantação e avaliação das políticas públicas voltadas para o combate à violência e à discriminação por orientação sexual, garantindo que o Governo Brasileiro inclua o recorte de orientação sexual e o segmento GLTB em pesquisas nacionais a serem realizadas por instâncias governamentais da administração pública direta e indireta (BRASIL, 2004, p. 11-12).
\end{abstract}

O Programa Brasil sem Homofobia pautou as diversas ações que deveriam ser criadas através das diversas ações, sendo elas divididas em áreas e cada uma com suas estratégias: a) Articulação da Política de Promoção dos Direitos de Homossexuais; b) Legislação e Justiça; c) Cooperação Internacional; d) Direito à Segurança: combate à violência e à impunidade; e) Direito à Educação: promovendo valores de respeito à paz e a não discriminação por orientação sexual; f) Direito à Saúde: consolidando um atendimento e tratamentos igualitários; g) Direito ao Trabalho: garantindo uma política de acesso e de promoção da nãodiscriminação por orientação sexual; h) Direito à Cultura: construindo uma política de cultura de paz e valores de promoção da diversidade humana; i)Política para a Juventude; j) Política para as Mulheres; k) Política contra o Racismo e a Homofobia.

Vamos apenas nos deter a realizar uma análise sobre o item que pontua sobre o Direito à Educação: promovendo valores de respeito a paz, a não violência e a impunidade. A escola é o lugar que a diversidade se manifesta a todo instante e pensar em um ambiente que não promova o respeito ao "diferente" é, de certo modo, fugar-se das responsabilidades de criar mecanismo para que esse sujeito não evada da escola. Por esse motivo, o Programa Brasil sem Homofobia trata no que tange à escola os seguintes aspectos os quais deveriam serem adotados como forma de possibilitar um espaço democrático e, sobretudo, de ampliação da 
formação inicial e continuada dos profissionais que atuam na educação básica, como forma de propiciar ao educando uma escola igualitária para todos.

\footnotetext{
Elaborar diretrizes que orientem os Sistemas de Ensino na implementação de ações que comprovem o respeito ao cidadão e à não-discriminação por orientação sexual;

Fomentar e apoiar curso de formação inicial e continuada de professores na área da sexualidade;

Formar equipes multidisciplinares para avaliação dos livros didáticos, de modo a eliminar aspectos discriminatórios por orientação sexual e a superação da homofobia;

Estimular a produção de materiais educativos (filmes, vídeos e publicações) sobre orientação sexual e superação da homofobia; Apoiar e divulgar a produção de materiais específicos para a formação de professores;

Divulgar as informações científicas sobre sexualidade humana;

Estimular a pesquisa e a difusão de conhecimentos que contribuam para o combate à violência e à discriminação de GLTB;

Criar o Subcomitê sobre Educação em Direitos Humanos no Ministério da Educação, com a participação do movimento de homossexuais, para acompanhar e avaliar as diretrizes traçadas (BRASIL, 2004, p. 22).
}

Embora, o Programa Brasil sem Homofobia evidencie diversas possibilidades para criação de políticas públicas para a valorização de uma educação sem discriminação por orientação sexual, e promoção dos direitos da população LGBTTIQ não houve uma efetivação legítima desta política. Já o Plano Nacional de Promoção da Cidadania e Direitos Humanos dos $\operatorname{LGBT}^{10}$ aprovado em 2009, também acrescenta diversos tópicos que deveriam ser concretizados para efetivar as políticas públicas no âmbito da educação para valorização da diversidade sexual, das identidades de gêneros e das multiplicidades das pessoas que compõem a população LGBT.

No entanto, o cenário que constituiu-se a partir do lançamento do Plano que analisaremos no próximo tópico foi de retrocessos e de não aplicação das políticas públicas pontuadas nos documentos anteriores. A não efetividade aconteceu em virtude do crescimento dos setores conservadores no Congresso Nacional, em especial, da banca evangélica que não compreende os direitos da população LGBTTIQ e os acusam de praticar um denominada “ideologia de gênero" ${ }^{11 " . ~ A m p l i a r e m o s ~ a s ~ d i s c u s s o ̃ e s ~ s o b r e ~ a s ~ p o l i ́ t i c a s ~ p u ́ b l i c a s ~ q u e ~ f o r a m ~}$ ineficazes no próximo tópico.

\footnotetext{
${ }^{11}$ A "ideologia de gênero" é uma expressão usada pelos críticos da ideia de que os gêneros são, na realidade, construções sociais. Para os defensores desta "ideologia", não existe apenas o gênero "masculino" e "feminino", mas um espectro que pode ser livremente escolhido pelo indivíduo. A chamada "ideologia de gênero" representaria o conceito que sustenta a identidade de gênero. Consiste na ideia de que os seres humanos nascem "iguais", sendo a definição do "masculino" e do "feminino" um produto histórico-cultural desenvolvido tacitamente pela sociedade.
} 


\section{Políticas Públicas no Brasil e o Movimento LGBTTIQ}

O Estado na tentativa de garantir e efetivar os direitos previstos na Constituição Federal desenvolve as políticas públicas que são um conjunto de ações e programas que estão presente em todas as áreas, como saúde, educação, segurança, moradia, transportes, trabalho, assistência social e meio ambiente. Além dos direitos garantidos constitucionalmente podem ser criadas políticas públicas com direitos que são identificados como necessidade de parte da sociedade.

Em 2009 foi criado o Plano Nacional de Promoção da Cidadania e Direitos Humanos dos LGBT, visando criar orientações para diversas políticas públicas que venha ao encontro da necessidade de um grupo social que reivindica uma mudança histórica-social, jurídica e política do país.

Ao verificarmos o contexto histórico compreendemos que é quase irrisória as políticas públicas destinada a população LGBTTIQ e, quando existentes estão voltadas apenas a área da saúde, ainda arraigada ao preconceito que a proliferação do vírus HIV acontece apenas através da LGBTTIQ.

Com a ascensão dos movimentos LGBTTIQ no Brasil, especialmente nos últimos anos, diante do descontentamento; manifestações contrárias as políticas e a forma como o governo enfrenta as pautas levantadas pelo movimento é possível compreender o que Ruas destaca

\footnotetext{
Trata-se de um "estado de coisas" - algo que incomoda, prejudica, gera insatisfação, para muitos indivíduos, mas não chega a construir um item da agenda governamental, ou seja, não se encontra entre as prioridades dos tomadores de decisão. Quando este estado de coisas passa a preocupar as autoridades e se toma uma prioridade na agenda governamental, então tornou-se um "problema político" (2009, p. 5).
}

A implementação de políticas públicas para a população LGBTTIQ+ entrou em um campo de disputa política entre os favoráveis à garantia dos direitos do referido grupo e, de outro lado, os que são contrários ao cumprimento desses direitos. Nessa perspectiva é fundamental pensar que os tomadores de decisão, como pontua Ruas, deveriam zelar pelo cumprimento da Carta Magna, no entanto em sua maioria votam contrário baseando-se em argumentos religiosos e conservadores. 
As políticas públicas no que tange a população LGBTTIQ+ estão no grupo ações que não necessitam de um alto valor econômico, mas desenvolvem alto impacto social em virtude da influência de setores da sociedade tais como Igreja e outros setores conservadores. Por estes motivos, encontram tamanhas dificuldades de serem implementadas ou quando implementadas de serem continuadas, pois acabam ocupando o espaço de políticas de governo e não de Estado.

A pauta para o desenvolvimento das políticas públicas está ligada às agendas de governo, e ao grupo ao qual ele pretende representar, através do campo político em que está inserido. No entanto, é fundamental destacar, que embora o Executivo tenha interesse em realizar uma ampliação de políticas públicas a um grupo social, o legislativo pode barrar essas ações caso não venham ao encontro de suas aspirações. Podemos verificar esta omissão ou descaso em tratar esta política pública, através dos Planos Municipais, Estaduais, Distrital e Federal de Educação que não acatam as recomendações do Plano Nacional de Promoção da Cidadania e Direitos Humanos dos LGBT que pontuava

\begin{abstract}
Estruturar metodologia que permita categorizar as questões de orientação sexual e identidade de gênero no sistema de coletas de dados educacionais, para o acompanhamento e a avaliação das políticas públicas de educação, incluindo indicadores de violência por motivo de orientação sexual e de identidade de gênero (BRASIL, 2009, p. 32).
\end{abstract}

Mesmo com a recomendação da política pública a execução dela foi negada em quase todos os estados da federação e foram excluídas todas as referências aos termos gênero, sexualidade e identidade gênero dos planos, sob alegação que não competiria à escola tal abordagem. Com isso verificamos que embora exista a garantia nos diversos documentos, se faz necessária a ampliação das discussões da promoção destes direitos nas escolas. É possível vislumbrar por meio do descaso com estes valores, de como os "tomadores de decisão" desconsideram todas as agendas emergentes e se manifestam baseados em valores morais e religiosos do passado.

Toda essa concepção de valores foram retiradas dos planos de educação, sob a alegação da doutrinação nos bancos escolares e da "destruição da família" - considerando aqui apenas o modelo de família tradicional formado por um casal heterossexual cisgênero ${ }^{12}$. Nesse sentido, é fundamental compreender que "a política pública permite distinguir o que o governo pretende fazer e o que, da fato, faz" (SOUZA, 2006, p. 36).

\footnotetext{
${ }^{12}$ É a autoidentificação com características físicas, sociais e culturais vinculadas ao gênero que corresponde ao sexo que lhes foi atribuído com base em seus aspectos corporais ou anatomicos.
} 


\section{Plano Nacional de Promoção da Cidadania e Direitos Humanos dos LGBT e a educação}

Entre os dias 05 e 08 de junho de 2008, ocorreu em Brasília a 1ª Conferência GLBT, com objetivo de debater, criar metas e ações que logo mais integrou as estratégias que orientavam a criação de políticas públicas para a população LGBT.

O Plano Nacional de Promoção da Cidadania e Direitos Humanos das LGBT foi criado em 2009, pela Secretaria Especial de Direitos Humanos da Presidência da República e tinha em seu objetivo central dar continuidade nas discussões iniciadas através do Programa Brasil sem Homofobia. Tal iniciativa tentava atender as demandas da população LGBT que buscava por políticas públicas, para a promoção do respeito aos atores sociais que durante muito tempo tiveram seus direitos negados pelo conservadorismo.

O Plano para sua execução baseiava-se em 51 diretrizes que contemplasse as diversas áreas a saber,: saúde, educação, cidadania, trabalho, moradia e política. Nos deteremos apenas nas diretrizes para abordagem do tema na área das políticas públicas e da educação que é o foco desse trabalho.

Em suas diretrizes o plano reverbera o Artigo $6^{\circ}$ da Constituição Federal e pontua os seguintes itens:

5.13. Inserção da temática LGBT no sistema de educação básica e superior, sob abordagem que promova o respeito e o reconhecimento da diversidade da orientação sexual e identidade de gênero;

5.23. Intersetorialidade e transversalidade na proposição e implementação das políticas públicas: o combate à homofobia requer ações integradas entre as áreas da educação, saúde e segurança, dentre outras;

5.29. Educação e informação da sociedade para o respeito e a defesa da diversidade de orientação sexual e identidade de gênero;

5.46. Desenvolvimento de ações e práticas de Educação em Saúde nos serviços do SUS e de Educação em Saúde nas Escolas com ênfase na orientação sexual e identidade de gênero; (BRASIL, 2009, p. 13-18)

Observa-se nas diretrizes elencadas que havia uma preocupação com o processo educativo da população LGBT no Brasil, visando o acesso e a permanência desse grupo social no ambiente escolar. Tal medida não acontece, pois devido à ausência de formação dos profissionais que atuam na escola, bem como a não discussão do tema em sala de aula, a escola. Torna-se um lugar de reprodução de preconceitos e, por vezes, "expulsa" o estudante através da denominada evasão escolar. Em vista disso, apenas reproduz a hegemonia construída ao longo de décadas nas escolas públicas, onde preconiza acima de tudo a valorização e oportunização dos melhores resultados aos grupos historicamente aceitos socialmente. Seffner destaca que 


\begin{abstract}
A escola pública brasileira, tradicionalmente, atuou também como um dispositivo que contribuía para manter e até mesmo acentuar a desigualdade, promovendo a expulsão (muitas vezes chamada de evasão) dos indivíduos de grupos sociais hierarquicamente inferiores, tais como os não brancos, os indígenas, as mulheres, os homossexuais, os moradores das regiões rurais e da periferia, os pobres em geral, aqueles oriundos de famílias ditas "desestruturadas", etc. Desta forma, os melhores índices escolares (e por consequência as melhores oportunidades na vida) ficavam com os indivíduos brancos, urbanos, homens, de classe média, heterossexuais, de pertencimento católico (praticante ou não), não portadores de deficiência, entre outras marcas positivas (SEFFNER, 2011. p. 105)
\end{abstract}

Nesse sentido, pensar em políticas públicas para a educação que venham ao encontro desta camada da sociedade, é fundamental na garantia do que propõem a Constituição de 1988, o Estatuto da Criança e do Adolescente, a Lei de Diretrizes e Bases da Educação, os Parâmetros Curriculares Nacionais e o Plano Nacional de Educação - PNE de 2002. Estes pontuam a necessidade de garantir acesso e permanência dos sujeitos no ambiente escolar. Cabe destacar que para efetivação de um processo educativo sem discriminação o PNE faz menção ao tema, contemplando desde a educação infantil até o ensino superior.

Além das diretrizes acima mencionadas também traça estratégias que deveriam ser desenvolvidas tais como: Estratégia I a) promoção e defesa da dignidade e cidadania LGBT, b) promoção e socialização do conhecimento, c) formação de atores, d) defesa e proteção dos direitos da população LGBT, e) sensibilização e mobilização de atores estratégicos. Estratégia II a) Implantação sistêmica das ações de promoção e defesa da dignidade e cidadania LGBT, b) Integração da política de promoção da cidadania LGBT com as demais políticas públicas, c) promoção da cooperação federativa, d) articulação e fortalecimento de redes sociais, e) articulação com outros Poderes, f) cooperação internacional, g) Gestão da implantação sistêmica.

As expectativas do PNE para a efetivação de uma Política Pública no que condiz a educação, tema elencado neste artigo, tem pautadas ações que tratam deste assunto.

1.1.1 Incluir recomendações relacionadas à promoção do reconhecimento da diversidade sexual e ao enfretamento ao preconceito e à violência por orientação e identidade de gênero nos Editais de Avaliação e Seleção de Obras Didáticas do Programa Nacional do Livro Didático (PNLD), do Programa Nacional do Livro Didático para o Ensino Médio (PNLEM) e do Programa Nacional do Livro Didático para a Alfabetização de Jovens e Adultos (PNLA).

1.1.2 Incluir a população LGBT em programas de alfabetização, instituir e ampliar programas e projetos na área de saúde e educação nas escolas públicas do país. 
1.1.3 Estimular e incluir as temáticas relativas à orientação sexual, identidade de gênero e raça/etnia nos currículos universitários, nas atividades de ensino, pesquisas de extensão, sem excluir nenhum campo do saber ou limitar a cursos da área da saúde.

1.1.4 Fomentar os temas relativos à "legislação e jurisprudência LGBT" no âmbito do Referencial para as Diretrizes Curriculares Nacionais - DCN dos Cursos de Graduação e das Diretrizes Curriculares Nacionais do curso de graduação em Direito.

1.1.5 Fomentar e apoiar cursos de pós-graduação em parceria com as universidades públicas sobre diversidade sexual para professores, gestores e profissionais que atuam nas diferentes áreas da gestão pública.

1.2.2 Criar um projeto de cooperação público-governamental de extensão nas escolas públicas, utilizando produções artístico-culturais com temática de sexualidade, diversidade sexual e identidade de gênero, com recorte de raça e etnia, como forma de educar para a cidadania e inclusão.

1.2.33 Criar um programa de bolsas de estudo que incentive a qualificação ou educação profissional de Travestis e Transexuais em diversas áreas.

1.3.1 Inserir nos livros didáticos a temática das famílias compostas por lésbicas, gays, bissexuais, travestis e transexuais, considerando recortes de raça/etnia, orientação sexual, identidade de gênero e socioeconômica, os novos modelos de famílias homoafetivas, com ênfase nos recortes de raça/etnia, orientação sexual e identidade de gênero.

1.3.2 Incluir as temáticas relativas à promoção do reconhecimento da diversidade sexual nas ações de Educação Integral.

1.4.1 Estimular e fomentar a criação e o fortalecimento de instituições, grupos e núcleos de estudos acadêmicos, bem como a realização de eventos de divulgação científica sobre gênero, sexualidade e educação, com vistas a promover a produção e a difusão de conhecimentos que contribuam para a superação da violência, do preconceito e da discriminação em razão de orientação sexual e identidade de gênero.

1.4.2 Produzir e/ou estimular a confecção e a divulgação de materiais didáticos e paradidáticos e de materiais específicos para a formação de profissionais da educação para a promoção do reconhecimento da diversidade de orientação sexual e identidade de gênero, inclusive em linguagens e tecnologias que contemplem as necessidades das pessoas com deficiências.

1.4.3 Produzir, apoiar e divulgar pesquisas que analisem concepções pedagógicas, currículos, rotinas, atitudes e práticas adotadas no ambiente escolar diante da diversidade de orientação sexual e de identidade de gênero, para contribuir para a implementação de políticas educacionais voltadas para a superação do preconceito, da discriminação e da violência sexista e homofóbica.

1.4.4 Estruturar metodologia que permita categorizar as questões de orientação sexual e identidade de gênero no sistema de coletas de dados educacionais, para o acompanhamento e a avaliação das políticas públicas de educação, incluindo indicadores de violência por motivo de orientação sexual e de identidade de gênero.

1.4.5 Agregar as temáticas LGBT nos bancos de dados existentes da CAPES e do $\mathrm{CNPq}$

1.4.6 Incluir nos programas de distribuição de livros para as bibliotecas escolares obras científicas e literárias que abordem as temáticas de gênero e diversidade sexual para os públicos infanto-juvenis e adultos.

1.4.7 Regulamentar o art. 33 da LDB, no sentido de garantir que o ensino religioso, de caráter facultativo, contemple a multiplicidade de visões religiosas, a história das várias religiões e a natureza laica do estado brasileiro.

2.1.11 Estabelecer política pública para assegurar o respeito à orientação sexual e identidade de gênero nas casas estudantis mantidas pelo poder público e pela iniciativa privada, garantindo a hospedagem de travestis e transexuais, respeitando sua identidade de gênero. 
2.6.1 Criar no Ministério da Educação, bem como nos órgãos afins nas instâncias estaduais e municipais, uma coordenadoria especifica de políticas para LGBT (BRASIL, 2009, p. 21-40)

Muitas das ações pontuadas no Plano jamais foram executadas e nem existem perspectivas para sua execução. No que tange aos livros didáticos houve uma mudança nas representações de gêneros, porém em sua maioria não houve alterações no sentido de incluir os LGBTTIQ+. Na graduação houve uma ampliação das discussões das temáticas envolvendo o grupo social em voga, porém quase sempre cercada de resistência por parte dos setores conservadores que ocupam os mesmos espaços. Destaca-se que as universidades hoje atendem travestis e transexuais, através do nome social.

Quanto às ações de capacitação dos profissionais da educação básica estas estão ligadas apenas as formações continuadas através de extensões universitárias, porém as ações a serem desenvolvidas nas pós-graduações, que dispunha o documento estas não foram praticamente efetivadas. Cabe destacar que foram desenvolvidos diversos materiais didáticos e cartilhas pedagógicas no sentido de ampliação das discussões em sala de aula, no entanto ainda existe resistência dos professores na abordagem do tema.

Após o início da década de 2000 ampliou-se as pesquisas em nível de graduação e pós graduação no Brasil sobre os temas gênero, sexualidade, identidade de gênero, performatividade e teoria nas universidades. Estes fatos se devem pelo fato da política pública de ampliação das universidade públicas e a chegada de novos sujeitos ao ambiente universitário. Essa entrada tenciona o espaço heteronormativo e machista, ampliando os horizontes dos envolvidos, sobretudo, a população LGBTTIQ e as mulheres na produção de ciência através dos seus olhares.

As demais metas elencadas no Plano não foram efetivadas através das políticas públicas, em virtude do conservadorismo e do preconceito intrínseco da população, representantes do legislativo e do executivo que trazem preconceitos através da construção histórica, social, política e religiosa.

\section{Considerações Finais}

Fazendo uma retrospectiva de acesso do direito à educação no Brasil, e do cenário das políticas públicas voltadas à educação é possível compreender que houve um avanço no pensamento dos governos, seja por pressão popular ou por pauta governamental, estas as políticas foram criadas. No entanto, é evidente que as pressões por grupos conservadores não 
deixaram haver a garantia que as políticas pensadas, fossem implementadas e, posteriormente, avaliadas para sua continuidade ou não.

Apesar das fundamentações inquiridas, documentos e organização de agenda para implementação, que viesse a contemplar os atores sociais, e o governo ter abnegado pela agenda governamental Essa derrota na implementação das políticas públicas voltadas à educação, especialmente, no que tange a população LGBTTIQ pode estar relacionada a dois fatores: a) pressão por setores conservadores da sociedade, ocupantes de espaços de poder, e portanto seriam capaz de fazer tal exclusão e, por outro lado, b) a ausência de organização e articulação política entre a população LGBTTIQ para pressão política.

Faz-se necessário refletir sobre a construção histórica e social do Brasil visto que, ainda não compreende à educação como um direito garantido à todos, e a escola omite-se a realizar essas discussões estão negando o direito fundamental à população LGBTTIQ.

\section{Referências Bibliográficas}

BRASIL. Constituições Brasileiras: 1988.vol. VII. Brasília: Senado Federal e Ministério da Ciência e Tecnologia, Centro de Estudos Estratégicos, 2000h.

BRASIL.. Lei 8.069, 13 de julho de 1990. Dispõe sobre o Estatuto da Criança e do Adolescente e dá providências. Diário Oficial da União, Brasília, DF, 16 jul 1990.

BRASIL. Lei n. 9.394, 20 de dezembro de 1996. Estabelece as diretrizes e bases da educação nacional. Diário Oficial da União, Brasília, DF, 23 dez 1996.

BRASIL.. Parâmetros Curriculares Nacionais. Orientação Sexual. 1997.

BRASIL.. Lei n. 10.172, 9 de janeiro de 2001. Aprova o Plano Nacional de Educação e dá outras providências. Diário Oficial da União, DF, 10 jan. 2001. Disponível em: <www.mec.gov.b $>$.

BRASIL. Conselho Nacional de Combate à Discriminação. Brasil Sem Homofobia: Programa de combate à violência e à discriminação contra GLTB e promoção da cidadania homossexual. Brasília: Ministério da Saúde, 2004.

BRASIL. Plano Nacional de Promoção da Cidadania e Direitos Humanos dos LGBT. Secretaria Especial dos Direitos Humanos da Presidência da República. Brasília. 2009.

BRASIL. O Ministério Público e os direitos de LGBT: conceitos e legislação. Brasília: Procuradoria Federal dos Direitos do Cidadão, Ministério Público do Estado do Ceará. Brasília. 2017.

BUTLER, Judith. Problemas de gênero: feminismo e subversão da identidade. Rio de Janeiro: Civilização Brasileira, 1980. 
LOURO, Guacira Lopes. Currículo, Gênero e Sexualidade. Porto: Porto Editora, 2000.

LOURO. (org.). O corpo educado: pedagogias da sexualidade. 2. ed. São Paulo: Autêntica, 2001.

MEYER, Dagmar Estermann. Gênero e educação: teoria e política. In. LOURO, Guacira Lopes; FELIPE, Jane; GOELLNER, Silvana Vilodre. Corpo, Gênero e Sexualidade: um debate contemporâneo na educação. 9. ed. Petrópolis, RJ: Vozes, 2013.

SÃO PAULO. Diversidade sexual e cidadania LGBT. 2. Ed. São Paulo: Secretaria de Justiça e da Defesa da Cidadania, Coordenação de Políticas para Diversidade Sexual. 2017.

SAVELI, Esmeria Lourdes. A educação obrigatória nas constituições brasileiras e nas leis educacionais delas derivadas. Revista Contrapontos - Eletrônica, v.10, n.2, p. 129-146.2010.

SECCHI, Leonardo. Políticas Públicas. Conceito, esquema de análise, casos práticos. 2 ed. São Paulo: Cenage, 2012.

SECCHI, Leonardo. Análise de Políticas Públicas. Diagnóstico de problema e recomendações de soluções. São Paulo: Congage Learning, 2016.

SCOTT, Joan. Gênero: Uma categoria Útil de Análise Histórica. Educação e Realidade.nº. 20,p. 71-99. 1995.

SEFFNER, Fernando. Escola para todos: mesmo para aqueles que manifestam diferenças em sexo e gênero. In. SILVA, Fabiane Ferreira da; MELLO, Elena Maria Billig. Corpos, gêneros, sexualidades e relações étnico-raciais na educação. Uruguaiana - RS: UNIPAMPA, 2011.

SEFFNER, Fernando; PICCHETTI, Yara de Paula. A quem tudo quer saber, nada se lhe diz: uma educação sem gênero e sem sexualidade é desejável?.Revista Reflexão e Ação, v. 24, n. 1, p. 61-81. 2016.

SOUZA, Celina. Políticas Públicas: uma revisão da literatura. Sociologias, v. 8, n. 16, jul-dez, 2006. 